\title{
Revisión bibliográfica de Implantología Bucofacial del año 2011. Primera parte
}

Bibliographic review of Oral Implantology of year 2011. Firts Part

\author{
SÁNCHEZ GARCÉS MA* \\ VUJANOVIC ESTENAZI $A * *$ \\ RUIZ IMATA L** \\ DÍAZ CAMPOS E** \\ MATEO VELÁZQUEZ M** \\ VALERO JAMES J** \\ NOGUEIRA MAGALHÃES P** \\ HERRANZ APARICIO J** \\ GAY ESCODA C***
}

Sánchez Garcés MA, Vujanovic Eskenazi A, Ruiz Mata L, Díaz Campos E, Mateo Velázquez M, Valero James J, Nogueira Magalhães P, Herranz Aparicio J, Gay Escoda C. Revisión bibliográfica de Implantología Bucofacial del año 2011. Primera parte. Av Periodon Implantol. 2013;25, 1: 17-39.

\section{RESUMEN}

La gran diversidad de fuentes de información que nos proporciona la literatura científica junto al escaso tiempo de que disponen los profesionales de la Odontología para consultarlas, ha motivado a los autores de este artículo a efectuar una revisión de la literatura científica publicada a lo largo del año 2011 en el campo de la Implantología Bucofacial. Con este fin se han agrupado los diferentes artículos consultados de revistas indexadas, en distintos apartados (generalidades, plan de tratamiento, pacientes especiales, superficies y diseño de los implantes, implantes inmediatos, carga inmediata, periimplantitis y complicaciones), con el fin de facilitar una buena puesta al día.

PALABRAS CLAVE: Implantología bucofacial, plan de tratamiento, pacientes especiales, complicaciones en implantología bucal, superficies y diseño, carga inmediata, implantes inmediatos, periimplantitis.

\section{SUMMARY}

The diversity existing in the multiple scientific literature information sources and the lack of available time to consult them, have encouraged the authors of this paper to carry out a review of the scientific literature published in year 2011 regarding Oral Implantology.Thus, we classified the articles into different categories (generalities, tatreatment planning, special patients, surfaces and design, immediate implants, immediate loading, periimplantitis and complications), so a more comprehensive updating can be made. del Máster de Cirugía Bucal e Implantología Bucofacial. Facultad de Odontología de la Universidad de Barcelona. Investigadora del Instituto IDIBELL.

** Licenciado en Odontología. Residente del Máster de Cirugía Bucal e Implantología Bucofacial. Facultad de Odontología de la Universidad de Barcelona.

*** Doctor en Medicina. Estomatólogo. Especialista en Cirugía Maxilofacial. Catedrático de Patología Quirúrgica Bucal y Maxilofacial. Director del Máster de Cirugía Bucal e Implantología Bucofacial. Facultad de Odontología de la Universidad de Barcelona. Investigador coordinador del Instituto IDIBELL. Jefe del Departamento de Cirugía Bucal, Implantología Bucofacial y Cirugía Maxilofacial del Centro Médico Teknon. Barcelona.. 
KEY WORDS: Oral implantology, treatment planning, special patients, complications in oral implantology, surfaces and design, immediate implants, immediate load, periimplantitis.

Fecha de recepción: 20 de diciembre de 2012.

Fecha de aceptación: 15 de enero de 2013.

\section{GENERALIDADES}

Desde que empezó la aplicación clínica de los implantes dentales de titanio en los años 50, la Implantología Bucofacial ha cobrado una gran relevancia de tal manera que hoy en día el tratamiento rehabilitador con implantes dentales constituye la primera opción terapéutica en la restauración bucodental. Debido a sus altas tasas de éxito y supervivencia, tanto su uso como el lanzamiento de nuevos productos al mercado, se han visto incrementados año tras año en las últimas décadas. Gracias a los últimos avances en materiales y técnicas, hoy en día, a la gran mayoría de los pacientes que presentan algún tipo de deficiencia ósea, se les puede ofrecer una prótesis implantosoportada con un resultado predecible (1).

Sin embargo la Implantología moderna sigue acusando muchos de los problemas presentes desde sus inicios. La falta de criterios validados de éxito, clínicamente relevantes y centrados en el paciente, conlleva la publicación de numerosos artículos, muchos de ellos basados en la experiencia propia de los autores, tanto a la hora de recoger los datos, como a la hora de interpretar los resultados. Carr y cols. (2) proponen la elaboración de una guía práctica sobre la valoración de los criterios de éxito en Implantología Bucofacial y establecen una serie de factores a tener en cuenta para recoger la información necesaria. De esta manera los datos obtenidos por diferentes grupos de trabajo podrían ser recopilados para la facilitar la preparación de un metaanálisis en el que los resultados obtenidos tendrían un mayor valor científico y lo que es aun más importante, una interpretación clínica más clara.

Aunque sólo un $2 \%$ de los artículos publicados sobre Implantología Bucofacial evalúan los resultados del tratamiento basándose en la percepción del propio paciente, la mayoría de estos estudios demuestran una gran nivel de satisfacción de los pacientes tratados, tanto en los aspectos funcionales como estéticos de su rehabilitación implantosoportada y sus expectativas casi siempre son cumplidas ampliamente $(3,4)$.
Uno de las cuestiones más importantes, dado que la consecución de la oseointegración de un implante está altamente garantizada, es cuáles son las posibles situaciones o complicaciones que pueden aparecer en el futuro, durante el tiempo de su uso funcional con el paso de los años. La pérdida ósea marginal, aunque tolerada en los criterios de éxito, es en ocasiones irrelevante y en otras, negativamente sorprendente y sin causa identificable en apariencia. Un interesante metaanálisis de Laurell y Lundgren (5) valora la pérdida ósea marginal de los implantes dentales a los 5 años de función, tomando como criterios de inclusión: la presencia actual del sistema de implantes en el mercado, la aportación de pruebas radiológicas en el momento de la colocación de la prótesis y un seguimiento de 5 años, y que existan al menos dos publicaciones prospectivas, sobre el sistema de implantes analizados. Sorprendentemente sólo tres sistemas de implantes dentales cumplieron con los criterios de inclusión; AstraTech Dental Implant System (AstraTech AB, Molndal, Sweden), Branemark System (Nobel Biocare AB, Goteborg, Sweden), y Straumann Dental Implant System (Institute Straumann AG, Basel, Switzerland). Los 3 sistemas mostraron una pérdida ósea marginal inferior a la aceptada según los criterios de éxito. Dada la escasez de datos aportados en este artículo, podría consensuarse que uno de los requisitos exigibles a todos los sistemas de implantes que se lanzan al mercado debería ser, en el momento de su comercialización, que faciliten datos sobre la pérdida ósea marginal del implante a medio plazo ya que es ésta, hasta hoy, la mayor preocupación para valorar el futuro de los mismos.

Hoy en día sabemos que existen varios factores que contribuyen a la reabsorción del hueso marginal de un implante y entre otras consecuencias, a comprometer la estética de la restauración protésica; estos factores son: el trauma quirúrgico, la sobrecarga del implante, la periimplantitis, el diseño de la región cervical del implante, las características de la superficie del implante, la presencia del "micro-gap" a nivel de la unión implante-pilar, el tipo de conexión protésica, la posición del implante en relación a la cresta alveolar, la cantidad del hueso periimplantario y la distancia 
entre implante-implante o implante-diente. También existen factores técnicos, al contrario de lo que demostraron los estudios previos, en relación con la posición idónea del implante respecto al hueso alveolar; la literatura reciente nos indica que una posición más subcrestal (1-3 mm) podría, no sólo prevenir la reabsorción ósea del hueso marginal, sino favorecer la formación del mismo por encima de la conexión entre el implante y el pilar protésico y ofrecer una mejor estabilidad de los tejidos blandos.

Degidi y cols. (6), en un análisis histológico e histomorfométrico de 9 implantes colocados en humanos, encontraron que aquellos que fueron instalados a nivel subcrestal formaron hueso por encima de la unión implante-pilar, mientras que los que se instalaron a nivel crestal experimentaron pérdidas de hueso marginal equiparables a las previamente publicadas $(0,5-$ $1,5 \mathrm{~mm}$ ). Un detalle importante detalle a tener en cuenta es que todos los implantes presentaban un cambio de plataforma a nivel protésico ("platform switching") y una conexión interna de cono Morse. El cambio de plataforma disminuye los efectos del tejido conectivo inflamado sobre los niveles óseos periimplantarios y una conexión protésica de cono Morse ofrece un entorno libre de bacterias y micromovimientos y comporta una mayor estabilidad tanto a los tejidos blandos como a los tejidos duros.

El proceso de oseointegración de los implantes dentales es quizás el aspecto que ha sido más estudiado. Los fabricantes de diferentes sistemas de implantes participan en una carrera continua por conseguir una superficie implantaría que estimule este proceso biológico y en la medida de lo posible, lo acelere. Ivanovski y cols. (7) describen por primera vez el transcriptoma asociado con la oseointegración en un modelo humano, evaluando los perfiles de la expresión genética a los 4,7 y 14 días después de la inserción de un implante de titanio con una superficie microrrugosa y químicamente tratada. Esto supone un importante avance en este campo ya que facilita el conocimiento de los mecanismos celulares y moleculares de la oseointegración y abre las puertas a posibles estrategias para la mejora del mismo, como podrían ser la modificación de la respuesta del paciente o de la superficie del implante para conseguir un proceso de oseointegración diseñado a medida.

Otro importante avance en este campo viene de la mano de Kuchler y cols. (8) que administran Teriparatida a los pacientes durante las primeras 4 semanas del proceso de oseointegración, a las 9 se- manas los implantes fueron retirados para su estudio histomorfométrico. La Teriparatida es una forma recombinada de la hormona paratiroidea que ha sido utilizada con éxito en los pacientes con osteoporosis para favorecer la cicatrización ósea tras una fractura y también en periodoncia para favorecer la formación de hueso en los defectos periimplantarios. Aunque los autores no encontraron diferencias estadísticamente significativas entre los grupos estudio y control debido al reducido tamaño de la muestra, afirman que el protocolo utilizado es un modelo válido para futuras investigaciones en esta dirección.

Un aspecto interesante a tener en cuenta, relacionado con el proceso de la oseointegración, es la posible alergia al titanio. Siddiqi y cols. (9) hicieron una revisión de la literatura y encontraron varias referencias de casos de hipersensibilidad al titanio e incluso fracasos de la oseointegración atribuibles a esta causa. Los autores postulan que la hipersensibilidad al titanio quizás no esté bien documentada en la literatura debido a su escaso conocimiento o porque no se considera como un posible factor etiológico del fracaso.

En definitiva, la Implantología Bucofacial está avanzando a pasos agigantados y a pesar de los problemas anteriormente mencionados todo indica que es una opción terapéutica altamente predecible. Aun así, no tenemos que olvidar que previamente al tratamiento siempre debe hacerse un correcto diagnóstico que se basará en un adecuado estudio clínico, radiológico y protésico y ante todo dirigido a satisfacer las demandas de los pacientes. Sólo de esta manera se podrán conseguir resultados predecibles y equiparables a los publicados en la literatura, sin olvidarnos que, en la gran mayoría de los casos, estos resultados vienen de la mano de cirujanos experimentados. Una adecuada formación teórica y clínica es la clave del éxito.

\section{PLAN DE TRATAMIENTO}

Un diagnóstico preciso y por consiguiente una adecuada planificación del tratamiento, junto con una correcta evaluación de los tejidos duros y blandos, son prerrequisitos indispensables para la obtención de unos resultados satisfactorios.

Las pruebas radiológicas más empleadas en Implantología Bucofacial para la evaluación preoperatoria son: la radiografía periapical, la ortopantomografía y la tomografía computadorizada (TC) y actualmente la tomografía computadorizada de haz cónico (Cone Bean 
Computer Tomography- CBCT) que va ganando terreno como prueba exploratoria complementaria. El éxito de la cirugía implantológica y restauradora muchas veces se sustenta en las técnicas de diagnóstico por la imagen (10).

Los métodos de diagnóstico por la imagen, principalmente la CBCT, ha contribuido de forma muy relevante a poder hacer una planificación más adecuada y por consiguiente obtener una reducción destacable de las complicaciones (10).

Las pruebas radiológicas más empleadas en el proceso de diagnóstico en Implantología Bucofacial siguen siendo la ortopantomografía y la TC aunque en los últimos años éstas están siendo relevadas por la CBCT como se ha mencionado anteriormente. Los sistemas de haz cónico han proporcionado enormes beneficios, tanto a los clínicos, por ofrecer unas imágenes con mayor resolución y por su reducido coste, como a los pacientes, por emitir unas dosis de radiación considerablemente más bajas además de que pueden obtenerse imágenes parciales y que pueden implementarse en el ámbito de una clínica dental.

La European Association for Osseointegration (EAO), ha publicado una nueva guía práctica sobre la utilización de las técnicas radiológicas en Implantología Bucofacial en respuesta al desarrollo de sus diferentes aplicaciones en cirugía implantológica y en prostodoncia, considerando no sólo el proceso de planificación, sino también su uso en la prevención y diagnóstico de las posibles complicaciones. La EAO recalca la importancia del uso apropiado de estas técnicas diagnósticas teniendo siempre en cuenta los principios básicos de justificación y optimización con el fin de obtener el máximo beneficio con el mínimo coste para el paciente. Consideran apropiado su uso en la valoración de defectos óseos y zonas donantes de injertos autólogos, en la planificación de la elevación del seno maxilar, para prever la mejor posición y angulación de los implantes, poder observar la cavidad nasal y la posición del conducto dentario inferior en sentido vestíbulo-lingual (11), también es imprescindible su uso en las técnicas especiales como es la instalación de implantes cigomáticos o la cirugía guiada y para la valoración de posibles complicaciones postoperatorias.

Es importante subrayar que cada caso debe ser evaluado de forma individual y que estas pruebas no deben ser aplicadas de forma rutinaria o antes de una buena valoración clínica, aunque varios autores coinciden en que el coste adicional de éstas pruebas diag- nósticas por la imagen más específicas y en 3D, está justificado y evita perder un tiempo adicional durante la intervención quirúrgica, ya que preoperatoriamente informa al cirujano de las limitaciones anatómicas no visibles en una imagen en $2 \mathrm{D}$ (12), aunque, debe tenerse en cuenta que la presencia de prótesis o restauraciones metálicas pueden generar artefactos en las imágenes y por consiguiente, disminuir considerablemente la calidad en algunos cortes (11).

Un buen ejemplo de la aplicación clínica de la CBCT podría ser la que Braut y cols. (13) proponen después de analizar el grosor de la cortical vestibular a nivel crestal de 498 dientes de la región anterior del maxilar superior. El $90 \%$ de los dientes presentaban una cortical inexistente o de un espesor menor de $1 \mathrm{~mm}$ y por lo tanto precisaban de alguna técnica regenerativa adicional en caso de exodoncia, algo que no se podría haber previsto con el uso de la radiografía convencional y que condiciona la técnica quirúrgica y la secuencia de tratamiento.

En realidad la ortopantomografía es la exploración radiológica más usada en Odontología puesto que permite obtener una visión general de los maxilares y de las estructuras adyacentes. Su uso en Implantología Bucal como única prueba diagnóstica es habitual, excepto en aquellas situaciones de compromiso óseo. Uno de los problemas de la ortopantomografía es la magnificación, que suele estar entorno al 1,2 y la distorsión que presenta, aunque autores como Yim y cols. (14) han demostrado que la utilización de objetos de un diámetro predeterminado permiten la calibración de las mediciones óseas verticales de forma fiable.

En comparación con la TC y la CBCT, la ortopantomografía es una prueba diagnóstica rápida y de bajo coste económico que se consigue con una baja dosis de radiación, pero de poca fiabilidad.

Previamente a la introducción de la TC, el mapeo de la cresta alveolar era uno de los métodos alternativos para medir la cresta alveolar residual. El mapeo puede sernos útil para seleccionar los casos, ya que nos proporciona información al momento de la altura y anchura de la cresta alveolar, evitando así solicitar una TC. Además, si el mapeo lo efectuamos junto a la confección de una férula quirúrgica podemos obtener información acerca de la topografía de la cresta residual en el lugar preciso en el que se planifica la colocación de un implante (15). La reabsorción de la cresta ósea residual es crónica, progresiva, irreversible y acumulativa y el mapeo puede ayudar al cirujano bucal a 
conocer si disponemos de una adecuada cantidad de tejidos duros y blandos y en el caso de que éstos sean insuficientes poder planificar su restitución (16). Luk y cols. (17) evaluaron las mediciones de la cresta alveolar previas a la intervención quirúrgica mediante TC y mapeo. Se observaron diferencias estadísticamente significativas entre el mapeo y la TC en todos los lugares estudiados, con una diferencia media de $0,4 \mathrm{~mm}$. Concluyeron que el mapeo está indicado para aquellos casos en los que se observa una reabsorción ósea leve o moderada, estableciendo la indicación de la TC en aquellos casos con una reabsorción severa.

Otro elemento importante a tener en cuenta en la planificación de un caso son el uso de las férulas quirúrgicas. En la actualidad el implante no debe simplemente colocarse donde exista hueso disponible, sino que también deben alcanzarse los objetivos protésicos exigidos en cada caso y para conseguirlos, las férulas quirúrgicas son de utilidad ya que permiten guiar la angulación y la posición de los implantes. Existen diferentes diseños ampliamente aceptados, aplicables a la cirugía abierta con control visual, que pueden adoptarse en función del tipo de edentulismo y las preferencias del cirujano, pero desde hace algunos años puede optarse también por un diseño propio para la aplicación en la cirugía sin colgajo.

En el estudio de Komiyama y cols. (18) se evaluó la desviación en el posicionamiento de las réplicas de los implantes en un modelo estereolitográfico preoperatorio y las réplicas de los implantes en un modelo estereolitográfico postoperatorio realizado a partir de las impresiones en el paciente un año después de la intervención quirúrgica. Se colocaron los implantes mediante el sistema de cirugía guiada Nobel Guide ${ }^{\circledR}$ (Nobel Biocare, Goteborg, Suecia) encontrando diferencias estadísticamente significativas en cuanto a la posición del ápice del implante entre los modelos preoperatorio y postoperatorio, existiendo una desviación media de 0,59 mm en el maxilar superior y de 0,40 mm en la mandíbula. Estos datos deben hacernos reflexionar acerca del uso de los sistemas de cirugía guiada mínimamente invasiva en casos de reabsorción ósea severa y cuando trabajamos en la cercanía de estructuras anatómicas nobles.

En definitiva, el diagnóstico implantológico correcto se basa en la interpretación adecuada de las demandas del paciente, de los estudios clínico, radiológico y protésico previos y a un conocimiento exacto de la anatomía local conjuntamente con la utilización de todos aquellos instrumentos y materiales necesarios para la correcta colocación de los implantes. Sin tener en cuenta todos estos factores, la cirugía implantológica no se puede considerar predecible y por consiguiente no se conseguirían los resultados esperados.

\section{PACIENTES ESPECIALES}

\section{Enfermedad periodontal}

Los pacientes con un mayor potencial de desarrollar enfermedad periimplantaria son los que padecen o han padecido una enfermedad periodontal agresiva generalizada, ya que presentan una mayor pérdida ósea y una menor tasa de supervivencia implantaria en comparación con los pacientes periodontalmente sanos o con enfermedad periodontal crónica avanzada.

En el estudio de Kehl y cols. (19) se evaluó la pérdida de hueso periimplantario y el grosor de encía queratinizada en sujetos con periodontitis crónica generalizada y periodontitis agresiva generalizada. El menor grosor y cantidad de encía queratinizada se localizó en la mandíbula en ambos grupos, y la mayor pérdida ósea se localizó en la zona vestibular. La pérdida de hueso fue más acusada en los pacientes con periodontitis agresiva generalizada. En conclusión, debido a que las enfermedades periimplantarias pueden provocar una pérdida de hueso alrededor de los implantes, es imprescindible hacer un diagnóstico precoz de la enfermedad periodontal así como efectuar visitas de seguimiento posteriores (19).

\section{Tabaquismo}

Numerosos estudios han evaluado el efecto del tabaco en relación con la supervivencia de los implantes dentales. Los efectos nocivos del tabaco incluyen: el retraso en la cicatrización de las heridas, la disminución en la producción de colágeno, el deterioro en la función de los fibroblastos, la disminución en la circulación periférica y el compromiso en la función de los neutrófilos y los macrófagos.

Se ha demostrado que el tabaquismo es un factor de riesgo para la pérdida temprana y tardía de los implantes, así como de complicaciones biológicas, como la periimplantitis, la mucositis y la pérdida de hueso marginal. La causa de estas complicaciones puede tener un origen multifactorial ya que los efectos tóxicos del tabaco son múltiples, afectando a la circulación sanguínea, actividad quimiotáctica de los leucocitos o 
a la síntesis de colágeno entre otras, como ya se ha especificado $(20,21)$.

En el estudio de Aglietta y cols. (20) se demostró que los fumadores con historia previa de periodontitis tratada tuvieron una supervivencia menor de los implantes y más pérdida de hueso periimplantario comparándolo con los fumadores periodontalmente sanos, independientemente de otros factores como el tipo de implante, si la cirugía fue en una o dos fases y de la habilidad del cirujano.

En el estudio de Rodríguez-Argueta y cols. (21) se evaluó el efecto del tabaco y el riesgo de padecer complicaciones en pacientes tratados con implantes dentales. Se incluyó en el estudio un total de 295 pacientes a los que se le colocaron un total de 1.033 implantes. Se reportaron un total de 209 complicaciones $(32 \mathrm{ca}-$ sos de pérdida del implante, 2 casos de infección, 70 casos de periimplantitis y 105 casos de mucositis). El hábito de fumar asoció a un mayor riesgo de padecer complicaciones tras el tratamiento implantológico (21).

El tratamiento con implantes dentales puede ser aplicado en fumadores, aunque debemos animar a los pacientes a que abandonen este hábito o al menos que disminuyan el consumo de cigarrillos.

\section{Diabetes}

Como es conocido hay dos tipos principales de Diabetes Mellitus (DM): DM tipo I, causada por una reacción autoinmune que destruye las células beta del páncreas y la DM tipo II producida por una resistencia a la insulina. La DM tipo II es la más prevalente entre la población adulta que suele ser la que con mayor frecuencia solicita tratamiento implantológico.

La DM está considerada como un factor de riesgo y una DM mal controlada es una contraindicación para el tratamiento con implantes dentales (22-24). Por el contrario, la supervivencia de los implantes es similar en pacientes con DM bien controlada respecto a pacientes sanos (22).

En el estudio de von Wilmowsky y cols. (23) se evaluó el contacto implante-hueso y la densidad de hueso periimplantario en cerdos diabéticos y sanos a los que se les colocaron implantes. Se observaron cambios patológicos en los tejidos duros y blandos de los cerdos diabéticos. El contacto implante-hueso y la densidad de hueso periimplantario fue significativamente menor en el grupo de cerdos diabéticos respecto al grupo de cerdos sanos. Por lo tanto, la DM afecta negativamente a la mineralización ósea y a la formación ósea en el área localizada alrededor de los implantes dentales.

\section{Pacientes tratados con bifosfonatos}

Los bifosfonatos (BF) son potentes inhibidores osteoclásticos, indicados para el tratamiento de algunas enfermedades que afectan al metabolismo óseo. Debido a su capacidad para disminuir el recambio óseo, también se han propuesto como fármacos útiles en el tratamiento único o coadyuvante de otras patologías óseas, como las lesiones de células gigantes, la osteogénesis imperfecta, la displasia fibrosa, la enfermedad de Gaucher o la osteomielitis.

En el año 2002, la Agencia Americana para el Medicamento (FDA) advirtió a las comunidades médica y odontológica del riesgo de aparición de osteoquimionecrosis de los maxilares (OQN) en los pacientes tratados con BF. Este tipo de complicación suele aparecer en aquellos pacientes a los que se les administran estos fármacos por vía endovenosa. Clínicamente se caracteriza por existir una exposición de hueso necrótico, que se acompaña de dolor y mal sabor de boca.

Existe un amplio consenso en la contraindicación absoluta del tratamiento con implantes en pacientes que padecen cáncer sometidos a terapia con BF intravenosos, debido al alto riesgo de desarrollar OQN.

En el estudio de Kim y cols. (25) se evaluó el efecto en ratas del alendronato en alvéolos postextracción y en el hueso periimplantario de ratas. El alendronato disminuyó la función de los osteoclastos, pero no afectó la función de los osteoblastos. El efecto de la supresión de la reabsorción ósea producida por los $\mathrm{BF}$, en este caso el alendronato, aumenta en el primer estadio de curación de los alvéolos postextracción, pero por el contrario, en el caso de los implantes la supresión de la reabsorción ósea se produce en etapas más tardías de la curación.

De todos modos, aunque el riesgo de aparición de una $\mathrm{OQN}$ en pacientes que toman $\mathrm{BF}$ orales para el tratamiento de la osteoporosis es menor que en los pacientes tratados contra el cáncer con BF por vía endovenosa, existe un pequeño riesgo que no debe ser menospreciado (26). 
Como clínicos debemos recomendar una revisión odontológica completa previa al tratamiento con BF y una vez iniciado el tratamiento realizar revisiones periódicas.

\section{Osteoporosis}

La osteoporosis es una enfermedad metabólica que afecta principalmente a las mujeres posmenopáusicas. Se caracteriza por una pérdida gradual de densidad ósea y el deterioro de la microarquitectura ósea inducida por un déficit funcional de los ovarios. La disminución de los estrógenos producidos por los ovarios, afecta negativamente al hueso localizado alrededor de los implantes (27). Esta falta de hueso periimplantario es debido a una menor actividad de los osteoblastos además de a un aumento de la actividad de los osteoclastos, produciéndose en consecuencia un menor contacto hueso-implante y un menor torque de inserción (28).

\section{Pacientes oncológicos y radioterapia}

Las zonas óseas que reciben radioterapia están asociadas a un riesgo 2-3 veces mayor de fracaso de los implantes, siendo especialmente alto cuando la dosis total es $=50$ Gy (29).

Las fuerzas mecánicas localizadas en la unión huesoimplante están directamente relacionadas con la calidad de la formación ósea alrededor del implante. La radioterapia inhibe la formación ósea, hecho que produce una reducción de la resistencia a las fuerzas mecánicas. Por consiguiente, la adhesión mecánica entre el implante y el hueso disminuye tras la radioterapia, lo que produce un mayor riesgo de fracaso en pacientes irradiados (30).

La rehabilitación protésica con implantes en pacientes oncológicos mejora tanto sus condiciones estéticas como funcionales (31). En el estudio de Dholam y cols. (32) se evaluó la calidad de vida de pacientes afectados por cáncer de cabeza y cuello portadores de prótesis mandibulares implantorretenidas. Los pacientes refirieron mejoría en la masticación de alimentos sólidos y semisólidos además de en la fonación y la resonancia de la voz. Los autores concluyen que la reconstrucción y rehabilitación de la mandíbula afectadas por cáncer restaura al paciente anatómicamente, estéticamente y funcionalmente a niveles óptimos.

\section{COMPLICACIONES}

La colocación de implantes dentales es un procedimiento seguro, pero como cualquier procedimiento quirúrgico puede presentar complicaciones, cuyo conocimiento es necesario para hacer su prevención.

Antes de iniciar su descripción debe establecerse la distinción entre los conceptos de accidente y complicación. Los accidentes se definen como eventos imprevistos que ocurren durante la intervención quirúrgica. En cambio, las complicaciones aparecen posteriormente, una vez finalizado el acto quirúrgico, diferenciándose a su vez entre tempranas y tardías según el momento de su aparición.

Entre los accidentes podemos incluir: lesiones de los tejidos blandos, lesiones vasculares, lesiones nerviosas, perforaciones en las fosas nasales o en los senos maxilares, dehiscencias y fenestraciones óseas, lesiones de los dientes vecinos, rotura de instrumentos, ingestión o inhalación de instrumentos o componentes mecánicos y falta de estabilidad primaria del implante. Las complicaciones tempranas incluyen la infección, edema, equimosis y hematomas, enfisema, sangrado, dehiscencia de la herida, y la aparición de alteraciones sensitivas. Por último, dentro de las complicaciones tardías se encuentran la sinusitis maxilar, fractura mandibular, fracaso de la oseointegración, defectos óseos, lesiones periimplantarias e infecciones (33).

\section{Accidentes}

\section{Malposición o mala angulación de un implante (axialmente, anteroposterior, transversal o verticalmente)}

Pueden afectar el éxito y la longevidad de una rehabilitación protésica. La corrección protésica de los implantes malposicionados puede hacerse utilizando coronas clínicas largas o con el uso de cerámica rosa, sin embargo este método puede resultar en una relación corona-implante desfavorable, con un resultado antiestético y en restauraciones inestables desde el punto de vista biomecánico (34). Otra opción para corregir este problema es el tratamiento quirúrgico. Oduncuoglu y cols. (35), describen la reubicación de un implante oseointegrado en posición muy apical, utilizando una técnica de distracción osteogénica. La distracción se realizó a $1 \mathrm{~mm}$ por día y terminó cuando el implante pudo desplazarse $6 \mathrm{~mm}$ en sentido coronal. Después de una fase de consolidación de 8 se- 
manas, se llevó a cabo una restauración implanto-soportada con prótesis fija.

\section{Sangrado excesivo}

Es un posible accidente inherente a cualquier intervención quirúrgica. Existen situaciones en las que los pacientes pueden presentar una mayor tendencia al sangrado, como es el caso de los pacientes con trastornos de la coagulación o con variaciones anatómicas de la situación de sus vasos sanguíneos. No obstante, en los casos en los que el paciente está descoagulado farmacológicamente, se pueden efectuar tratamientos invasivos como la cirugía implantológica sin alterar o interrumpir la pauta de administración de los medicamentos. Bacci y cols. (36), evaluaron la incidencia de complicaciones hemorrágicas después de la colocación de implantes en un grupo de 50 pacientes consecutivos que recibían tratamiento con anticoagulantes orales (warfarina), demostrando que la cirugía de implantes dentales en pacientes anticoagulados se puede llevar a cabo de forma segura y en régimen ambulatorio con la simple aplicación de hemostáticos y medidas locales. El número de complicaciones hemorrágicas no fue estadísticamente significativo al comparar los pacientes anticoagulados y los del grupo control.

Varios estudios alertan de que la colocación de implantes en la zona anterior de la mandíbula no es una técnica quirúrgica tan segura como puede creerse debido al riesgo de hemorragia por la lesión de la arteria sublingual (37). Katsumi y cols. (38), describen cuatro patrones o variaciones anatómicas en que podría ser clasificada la situación de las arterias submentoniana y sublingual que suministran riego sanguíneo a las estructuras anatómicas del suelo de la boca, y sugieren que la arteria submentoniana en el tipo de II, III y IV es susceptible a las lesiones durante la cirugía implantológica.

\section{Desplazamiento de un implante dentro del seno maxilar}

Es una complicación reportada en múltiples artículos. Esta complicación se puede producir durante la intervención quirúrgica o durante la fase de curación del implante por falta de estabilidad primaria. Sin embargo, también se publican casos de migración de implantes al seno maxilar en etapas posteriores. Galindo-Moreno y cols. (39), describen dos casos de desplazamiento de implantes después de 6 meses tras su inserción en senos maxilares injertados (sinus lift), estos desplazamientos ocurrieron a pesar de haber comprobado histológicamente la maduración del injerto y la estabilidad primaria del implante. Las complicaciones asociadas a la migración de un implante pueden ser: la movilidad de la rehabilitación protésica $(46,7 \%)$, sinusitis aguda (13,3\%), inflamación gingival bacteriana $(6,7 \%)$ o infección fúngica $(6,7 \%)$. Aproximadamente una cuarta parte de los pacientes $(26,7 \%)$ no presentan síntomas y son diagnosticados en exámenes de rutina (39). Galindo-Moreno y cols. (40), demostraron que la incidencia de migración del implante en la cavidad sinusal es mayor para los implantes cilíndricos en comparación con los cónicos, para los implantes de diámetro reducido y cuando se colocan implantes en pacientes fumadores.

\section{Fractura mandibular}

Durante la colocación de implantes se asocia normalmente a pacientes con mandíbulas atróficas. Soehardi y cols. (41), en un estudio retrospectivo estimaron que la incidencia de fracturas mandibulares es de alrededor de un $0,05 \%$. Además, este estudio reveló que todas las fracturas ocurren en mandíbulas con una altura ósea igual o menor de $10 \mathrm{~mm}$ (clase VI de Cawood y Howell), la mitad de estas suceden durante la colocación del implante o dentro del primer año, mientras que la otra mitad en los años siguientes a la colocación como resultado de la pérdida de hueso periimplantario.

\section{Lesiones nerviosas}

Pueden presentarse como un accidente intraoperatorio o como una complicación postoperatoria, que en cirugía implantológica suele afectar a los nervios infraorbitario, dentario inferior, mentoniano y lingual. Es importante saber que el nervio dentario inferior es el que se lesiona con mayor frecuencia $(64,4 \%)$, seguido por el nervio lingual (28,8\%) (42). Es especialmente importante evaluar los posibles factores de riesgo relacionados con la lesión del nervio dentario inferior dada su incidencia. Dependiendo del momento de aparición se puede clasificar como accidente intraoperatorio o postoperatorio. Los factores etiológicos intraoperatorios pueden ser agrupados según el mecanismo como se ha producido la lesión: mecánico, térmico y químico, y los factores de riesgo postoperatorios suelen ser indirectos, debido a estímulos térmi- 
cos, la infección periimplantaria y los hematomas. Según un estudio de Juodzbalys y cols. (42), el factor de riesgo más frecuente $(50 \%)$ fue el sangrado intraoperatorio durante la preparación del lecho implantológico y el mayor factor de riesgo causal de la lesión del nervio dentario inferior es el propio implante dental $(56,3 \%)$.

\section{Complicaciones}

\section{Infección del implante}

Es una de las principales causas de fracaso de los implantes. Las infecciones alrededor de los biomateriales son difíciles de tratar y casi todos los implantes infectados tienen que ser retirados. En general, la profilaxis con antibióticos en cirugía implantológica está solamente indicada en los pacientes con riesgo de desarrollar endocarditis bacteriana, en pacientes con inmunidad disminuida, cuando la cirugía se efectúa en zonas infectadas, en casos de intervenciones quirúrgicas prolongadas y cuando hacemos regeneración ósea guiada (43). Se han sugerido varios regímenes profilácticos de antibióticos por vía sistémica para reducir las infecciones después de la colocación de implantes dentales; pero en el caso que deba usarse un antibiótico, los protocolos más recientes recomiendan la profilaxis a corto plazo. Sharaf y cols. (44), hicieron una revisión de la literatura concluyendo que no hay pruebas científicas fiables para recomendar o rechazar el uso de antibióticos sistémicos con fines profilácticos o para prevenir las complicaciones y los fracasos de los implantes dentales.

\section{Osteonecrosis}

Los bifosfonatos (BF) constituyen un grupo de fármacos capaces de modular el recambio óseo y disminuir su remodelado cuando existe una reabsorción excesiva, considerándolos seguros y efectivos para el tratamiento de enfermedades con reabsorción ósea como la osteoporosis, la enfermedad de Paget y la hipercalcemia relacionada con enfermedades malignas. En los últimos años y a raíz de su utilización masiva se han publicado numerosos casos de complicaciones asociadas a su uso como la osteoquimionecrosis de los maxilares (OQN). La literatura reporta una prevalencia de OQN entre el $5 \%$ y el $12 \%$ para los pacientes que reciben $\mathrm{BF}$ intravenosos y entre $0,01 \%$ y $0,04 \%$ para los que usan BF orales (45). Hay poca evidencia sobre el riesgo de desarrollar OQN al colocar implantes den- tales en pacientes bajo tratamiento con $\mathrm{BF}$ orales, sin embargo, en pacientes bajo tratamiento con BF por vía intravenosa la colocación de implantes se considera un factor de riesgo, por lo que se establece como una contraindicación absoluta (46).

Sin embargo investigaciones en modelos animales han reportado que los BF pueden incrementar la oseointegración de los implantes dentales. Tsetsenekou y cols. (47), efectuaron un estudio en conejos y concluyeron que la administración sistémica de alendronato no influye en las primeras etapas de la integración del implante situado en el cóndilo del fémur en conejas ovariectomizadas y no detectaron diferencias significativas en la oseointegración a las 6 y 12 semanas entre el grupo experimental y el grupo control. Lee y cols. (48), hicieron un estudio en donde trataron la superficie de los implantes nanoestructurados con ibandronato y concluyeron que esta nueva superficie aumentó la biocompatibilidad del implante, promoviendo la formación del hueso adyacente y acelerando el proceso de oseointegración.

Respecto a otras complicaciones o accidentes incluidos en la clasificación comentada previamente no se han publicado artículos durante el año 2011 . La periimplantitis, una complicación tardía de alta incidencia, merece un capítulo aparte y las complicaciones específicas de otras técnicas quirúrgicas serán comentadas en el capítulo correspondiente.

\section{PERIIMPLANTITIS}

Durante los últimos años las complicaciones biológicas de los implantes dentales han aumentado su frecuencia. La enfermedad periimplantaria o periimplantitis se caracteriza por la inflamación de los tejidos periimplantarios y la pérdida de soporte óseo. Se han sugerido diferentes tipos de protocolos para el tratamiento de la periimplantitis no siendo ninguno de ellos concluyente como tratamiento $100 \%$ efectivo, no obstante el tratamiento quirúrgico permite el acceso a la superficie del implante y a la remoción de la placa bacteriana que se acumula sobre la superficie del implante (49-5l).

Según los últimos estudios la prevalencia de mucositis y periimplantitis es del $50 \%$ en los implantes colocados, y llega del 70 al $79 \%$ de los pacientes donde al menos uno de los implantes presenta una de estas dos complicaciones, no obstante, se han publicado diferentes datos sobre su prevalencia, determinada en la 
mayoría de los casos con diferentes criterios diagnósticos, por la elección de los pacientes incluidos y por el tipo y diseño del estudio $(50,52)$.

En cuanto a la sintomatología asociada a la periimplantitis, en muchos casos suele ser asintomática y casualmente es detectada en los controles periódicos al encontrar sangrado al sondaje, aplicando una fuerza inferior a los 0,25 Ncm (excepto en algunos fumadores ya que el tabaco posee potentes toxinas que producen vasoconstricción gingival) y por la pérdida de soporte óseo evidenciado radiológicamente $(50,53)$.

Los principales factores de riesgo asociados a la periimplantitis son: la mala higiene bucal, la retención en el surco gingival de los materiales utilizados en el cementado de las coronas, historia previa de periodontitis, tipo de superficie y diámetro de los implantes, factores genéticos y el tabaquismo $(50,52,53)$. Los implantes de mayor diámetro son más susceptibles a la perdida de soporte óseo en cambio aquellos de menor diámetro presentan problemas de infección con mayor facilidad (49). El momento de la carga protésica del implante parece no tener ninguna influencia sobre la perdida de soporte óseo (51).

Según los últimos estudios sobre los genotipos IL-1, IL-2, IL-6, TFN-A y el TGF-Bl se ha visto que no se encuentra una clara evidencia de asociación a una mayor predisposición a la periimplantitis aunque en los resultados de algunos estudios se relaciona el genotipo IL-1 como coadyuvante al incremento de infección y pérdida ósea periimplantaria $(52,54)$. En el maxilar superior la profundidad de las bolsas, el índice de sangrado y el grado de reabsorción ósea es significativamente mayor en los pacientes fumadores pero esta influencia no ha podido ser confirmada en la mandíbula $(50,53)$.

Los nuevos tratamientos no quirúrgicos de la periimplantitis usando el láser de Er:YAG o el aire abrasivo aplicados sobre la superficie del implante no refieren aportar una ventaja sólida frente al tratamiento quirúrgico, sin embargo en algunos estudios durante el periodo de seguimiento de los implantes tratados con estas técnicas, alrededor del $50 \%$ presentaban mejoría tanto clínica como microbiológica (55-58).

En términos generales, en los casos incipientes de periimplantitis el tratamiento consiste en la eliminación mecánica de la placa bacteriana y los enjuagues con clorhexidina al $0,12 \%$ cada $8 / 12$ horas durante 15 días, descontaminación de los aditamentos protésicos, tratamiento antibiótico y comprobación de un correcto diseño de la prótesis (56). Respecto al tratamiento antibiótico, la amoxicilina asociada con ácido clavulánico y la amoxicilina asociada con metronidazol o la eritromicina asociada a la tetraciclina durante 8 días, suelen ser los tratamientos más aceptados $(51,56)$.

La cirugía resectiva debe aplicarse cuando se encuentran perdidas óseas horizontales superiores a los $3 \mathrm{~mm}$ - ante la presencia de dehiscencias vestibulares en zonas no estéticas $(56,58)$. El protocolo de actuación respecto a la decisión de hacer tratamiento mecánico o quirúrgico depende del sangrado y el nivel de pérdida ósea. En profundidades de sondaje menores de 3 $\mathrm{mm}$ y con ausencia de placa bacteriana y sangrado no debe efectuarse ningún tipo de tratamiento. Ante profundidades de 4 a $5 \mathrm{~mm}$ sin pérdida ósea debe realizarse una limpieza y descontaminación química de la superficie del implante. Ante pérdidas óseas de $2 \mathrm{~mm}$ - menores se debe incluir la terapia antibiótica y en los casos en que supera los $2 \mathrm{~mm}$ el desbridamiento quirúrgico suele ser necesario $(50,52,59)$.

La adhesión bacteriana sobre la superficie del implante se basa en la colonización de las bacterias sobre un sustrato de restos extracelulares que se adhieren al titanio. Estudios "in vitro" demuestran la gran capacidad que tiene el Streptococcus aureus para adherirse a la superficie del implante $(57,58)$. Estudiando el tipo de bacterias presentes tanto en las periimplantitis como en la periodontitis, tras el estudio del biofilm, se ha visto que la composición bacteriana es similar, aunque la respuesta de los tejidos periimplantarios y periodontales es diferente a lo largo del tiempo $(60,61)$.

El control y el mantenimiento periódico de los implantes es crucial a la hora de prevenir la periimplantitis. Se ha demostrado que en pacientes con mucositis y sin mantenimientos periódicos el riesgo de desarrollar periimplantitis es del $43,9 \%$ siendo del $18 \%$ en aquellos sujetos que acuden a los controles y mantenimientos de forma periódica $(57,58)$

Ya que el tratamiento de la periimplantitis y su origen es bastante complejo, los pacientes deben seguir un estricto protocolo de mantenimiento visitando al menos cada 3 meses al higienista, realizando sondajes cada 6 meses y haciendo estudios tanto microbiológicos como radiográficos de forma periódica según el caso. Así mismo es de vital importancia instruir a los pacientes en relación con una correcta higiene de las prótesis (50). 


\section{SUPERFICIES Y DISEÑO DE LOS IMPLANTES}

Durante estos últimos años, la topografía de las microsuperficies de titanio (Ti) han sido ampliamente estudiadas con el fin de mejorar la integración y los resultados clínicos de los implantes dentales. Se han fabricado y comercializado múltiples tipos de superficies, desde las mecanizadas (lisas) hasta las rugosas tratadas con diferentes procesos fisicoquímicos.

Existe suficiente evidencia sobre la capacidad de las superficies rugosas en favorecer la aposición ósea sobre el implante de una forma segura y predecible. Basándonos en este hecho, se han propuesto diversas técnicas que permiten obtener una micro-rugosidad en la superficie de $\mathrm{Ti}$ con dos enfoques distintos. Uno de ellos es mejorar la superficie mediante técnicas de sustracción a través de arenado por compresión (partículas de sílice, de hidroxiapatita, de alúmina o de óxido de Ti, entre otras) y el grabado ácido (ácido fluorhídrico, ácido nítrico, ácido sulfúrico o combinaciones de los mismos). El tratamiento con un chorreado de arena frecuentemente es seguido de un grabado ácido para homogeneizar el micro-perfil y eliminar, en la medida de lo posible, las partículas residuales del material de chorreado.

Otra de las posibilidades de tratamiento de las superficies de los implantes es la que se hace mediante la incorporación de un revestimiento (adición) con elementos bioactivos y biomiméticos, tales como fosfato cálcico, flúor, o de una forma más experimental con factores de crecimiento, proteínas morfogenéticas y hormona del crecimiento.

La calidad y cantidad de aposición ósea estará directamente relacionada con las propiedades físicas y químicas de la superficie que posean los implantes tales como la composición iónica, la hidrofilia y la topografía de la rugosidad. Las características químicas de los implantes dependen tanto de su propia composición como del tratamiento de su superficie ya que ambas condicionan la absorción de las proteínas y la adhesión de las células sanguíneas. Se ha demostrado que las superficies mas hidrofílicas tienen una mejor interacción con los fluidos biológicos, células y tejidos (62). Estudios en animales y en humanos también concluyen que las superficies hidrofílicas tratadas con grabado ácido y chorreado de arena, generan un mayor contacto hueso implante que aquellas superficies obtenidas solo con grabado ácido o arenado (SLA) $(63,64)$.
Otra forma de tratamiento de la superficie de los implantes dentales es mediante el revestimiento con fosfato cálcico $(\mathrm{CaP})$, que después de la implantación, se libera en la región periimplantaria produciendo una saturación de los fluidos que da como resultado una precipitación de apatita sobre la superficie de contacto. Esta capa de apatita puede retener proteínas endógenas que actúan como matriz para la adhesión de células que aceleran la fijación entre la superficie de titanio y el tejido óseo. En un estudio de Artzi y cols. (65) obtienen un incremento significativo de contacto hueso-implante, si este último está recubierto con $\mathrm{CaP}$ respecto a los tratados con doble grabado ácido.

Los implantes químicamente modificados mediante la incorporación de iones de flúor han demostrado una mayor rapidez en la formación de hueso y una mayor fuerza en el contacto hueso-implante. El flúor estimula las células oseoprogenitoras y puede inhibir la activación de los osteoclastos a través de la formación de fluorapatita que es menos soluble; también incrementa la actividad de la fosfatasa alcalina (indicador de la formación ósea). En un estudio prospectivo (66) se evaluaron las tasas de supervivencia y éxito de los implantes con la superficie modificada mediante tratamiento con flúor a los que se les aplicó carga funcional inmediata, encontrando unas tasas de éxito y supervivencia del $100 \%$ por lo que concluyen que es un tratamiento altamente predecible.

Otro tipo de tratamiento por adición ha sido evaluado en un estudio experimental en perros (67) en el que compararon dos tipos de superficies implantológicas, una Straumann $®$ SLActive (Straumann $®$, Basel, Suiza) y la otra con doble grabado ácido y tratadas con nanocristales de fosfato cálcico (BIOMET $3 i \circledast$ Nano Tite, Palm Beach Gardens, Florida, EE.UU.) no encontrando diferencias entre ambas, ya que las dos superficies inducen un contacto hueso-implante de manera similar. Podría concluirse que, actualmente no existe evidencia de que algún tipo de superficie implantológica sea indudablemente mejor que otra.

Respecto al tipo de superficie del cuello de los implantes y la pérdida de hueso marginal, un estudio en humanos determinó que implantes con cuellos mecanizados o cuellos rugosos con microespiras tenían pérdidas mayores de hueso marginal, comparados con aquellos implantes rugosos con cuellos festoneados y con microespiras $(68,69)$.

Por otra parte en un artículo de revisión de la literatura se afirma lo contrario, que los implantes con cuellos me- 
canizados y los implantes con cuello rugosos sin microespiras tenían mayor pérdida de hueso marginal en comparación con los implantes rugosos con microespiras (70). La contradicción es patente, aunque de todos modos, ninguno de estos estudios reportó complicaciones, tales como mucositis o periimplantitis, a pesar de que posiblemente las superficies rugosas puedan favorecer en mayor medida la retención de placa bacteriana.

Albouy y cols. (71), indujeron una periimplantitis experimental en perros mediante ligaduras metálicas para determinar si las características de una superficie rugosa implantaría puede influir en el resultado del tratamiento de la periimplantitis. Compararon cuatro tipos de sistemas de implantes diferentes, que generaron unos resultados controvertidos, ya que en el único sistema en el que no se encontraron mejorías después del tratamiento fue el que poseía la superficie TiUnite (Nobel Biocare $®$ Inconnu, Denmark) comparado con las superficies Turned (Biomet $3 \mathrm{i} \circledast$ Nano Tite, Palm Beach Gardens, Florida, EE.UU.), TiOlast (AstraTech $® A B$, Göteborg, Suecia) y SLA (Straumann $® A G$, Basel, Suiza).

En cuanto al diseño de los implantes dentales, Bartold y cols. (72) estudiaron el grado de microdaños en la superficie ósea adyacente a los implantes durante la inserción en el lecho en relación con el diseño macroscópico y la superficie de los mismos, concluyendo que la inserción de un implante cilíndrico rugoso incrementa la fracción de microdaños de la matriz ósea periimplantaria con respecto a los implantes cilíndricos mecanizados y los implantes cónicos mecanizados y rugosos.

Se ha demostrado que la geometría de la interfase implante-pilar influye en el riesgo de invasión bacteriana de la parte interna del implante. En un estudio "in vitro" (73) se evaluaron dos grupos de implantes donde el grupo 1 estaba formado por implantes con conexión interna tipo "cono morse" que conectaba a pilares estándar y el grupo 2 estaba compuesto de implantes de conexión cónica interna con cuatro ranuras que conectaban a los pilares dinámicos. Se demostró que en el grupo 2 se formaban más colonias bacterianas, concluyendo que las diferencias en el diseño del implante pueden aumentar el riesgo potencial de colonización interna por microorganismos en condiciones de carga. Sin embargo en relación a las tensiones mecánicas que se producen dependiendo si es conexión interna, "cono morse" o externa, en un estudio de Nishioka y cols. (74) se concluye que no existen diferencias significativas.

Respecto al concepto "Platform Switching" (reducción de plataforma), estudios previos sugirieron que la dis- minución de la plataforma podría prevenir la pérdida ósea marginal. Diversos autores $(75,76)$ confirman esta hipótesis ya que, con una reducción de $0,25 \mathrm{~mm}$ en el diámetro del pilar respecto del diámetro del implante, consiguen disminuir la perdida ósea marginal. Por el contrario, en un ensayo clínico randomizado no se encontraron diferencias estadísticamente significativas al comparar implantes con y sin reducción de plataforma (77).

\section{CARGA INMEDIATA}

Las técnicas y tiempos implantológicos han cambiado mucho en los últimos años. Hasta hace relativamente poco, tras una exodoncia se debía esperar un cierto tiempo para asegurar la cicatrización de los tejidos, a continuación se procedía a la colocación de los implantes y tras un periodo de 3 a 6 meses se practicaba la carga funcional de los implantes de forma sistemática (78).

Esta modalidad tiene sin duda una alta tasa de éxito pero comporta tratamientos largos en el tiempo, intervenciones quirúrgicas múltiples y el uso de prótesis removibles durante el periodo de cicatrización $(78,79)$.

Con el aumento de las exigencias de los pacientes y el interés por resolver los problemas estéticos y funcionales relacionados con las segundas fases quirúrgicas, empezó a estudiarse el concepto de carga inmediata.

La carga inmediata se define como la colocación de los implantes en función dentro de las 48 horas del postoperatorio $(79,80)$.

La carga inmediata presenta algunas ventajas en relación con la carga convencional ya que reduce el tiempo total de tratamiento, se supone que existe una menor reabsorción de la cresta alveolar, tiene beneficios psicológicos para el paciente, permite un rápido restablecimiento de la función masticatoria, evita el uso de prótesis removibles que pueden interferir con el proceso de cicatrización y de regeneración ósea y disminuye el traumatismo quirúrgico $(78,80)$.

El maxilar superior se considera más complejo para rehabilitarlo mediante esta técnica ya que presenta un hueso de peor calidad y disponemos de menor cantidad de cresta ósea comparado con la mandíbula, exige una mayor demanda estética, dificulta la estabilidad primaria debida a la baja calidad ósea (lo que se reconoce como uno de los factores fundamentales para 
el éxito de la carga inmediata). Por estos motivos, se considera que el tratamiento con carga inmediata es más predecible en la mandíbula ya que normalmente presenta un tipo de hueso más denso. A pesar de que el maxilar superior suele tener un tipo de hueso más blando/trabecular se obtienen altas tasas de éxito y con buenos resultados si se efectúa una correcta técnica quirúrgica. $(78,80)$. Según la literatura, el éxito de la carga inmediata es comparable con el protocolo de dos fases quirúrgicas $(78,81-83)$.

Es importante diferenciar entre carga inmediata/función inmediata y la restauración inmediata/función no inmediata. En la primera la restauración es colocada ya en oclusión mientras que en la segunda la prótesis es colocada sin ocluir con los antagonistas evitando contactos estáticos o dinámicos con los dientes antagonistas. Estos términos son discutidos repetidamente en la literatura $(78,80)$.

Khorshid y cols. (84) en su estudio comparan la reabsorción ósea alrededor del implante cargado según el protocolo de carga inmediata y según carga progresiva, concluyendo que la reabsorción es menor cuando los implantes se someten a una carga progresiva.

En una revisión de la literatura, Chung y cols. (80) presentaron un listado de factores que se deberían tener en cuenta para lograr un tratamiento exitoso con carga inmediata tales como: la cantidad y cualidad del hueso alveolar, la tasa de formación de hueso en determinadas regiones del maxilar superior, práctica de exodoncias atraumáticas si son necesarias, una correcta estabilidad primaria del implante, posición del implante guiada por la prótesis, evitar cualquier tipo de hábitos parafuncionales, evitar la colocación de implantes inmediatos en alvéolos infectados, oclusión balanceada, un mínimo de $32 \mathrm{Ncm}$ de torque en la inserción del implante, intentar ferulizar los implantes entre ellos, una prótesis con ajuste pasivo y el uso de implantes de superficie rugosa $(78,80,83)$.

Strietzel y cols. (83), concluyen en un estudio retrospectivo, que la carga inmediata de implantes de superficie rugosa asociados a una prótesis fija atornillada es una opción de tratamiento predecible tanto en la mandíbula como en el maxilar superior y que presentan una tasa de éxito elevada en casos de carga inmediata, aunque aconsejan cautela en el uso de los implantes de tamaño igual o inferior a $10 \mathrm{~mm}$.

También Browaeys y cols. (85), refieren que las prótesis híbridas soportadas con implantes de superficie de grabado ácido sometidas a una carga inmediata constituye un tratamiento predecible a largo plazo.

Fung y cols. (79), en un ensayo clínico controlado, randomizado a boca partida, compararon implantes de superficie oxidada/anodizada con implantes mecanizados ambos cargados de forma inmediata para soportar una prótesis parcial fija en la zona posterior de la mandíbula. Tras 36 meses de estudio llegaron a la conclusión que estos 2 tipos de implantes no presentan diferencias significativas en relación a la reabsorción alrededor del implante y que esta es mínima. Concluyen que la rehabilitación de la zona posterior de la mandíbula con implantes de ambas superficies y según el protocolo de carga inmediata es un tratamiento predecible a largo plazo.

Elsyad y cols. (86), en un ensayo clínico randomizado con controles de 3 años compararon la perdida de hueso marginal alrededor de implantes que soportan una sobredentadura con anclajes de bola sometidos a carga inmediata o con carga convencional y concluyen que los implantes sometidos a carga inmediata sufren una mayor reabsorción del hueso marginal y una mayor profundidad de sondaje, sobretodo en las zonas distal y vestibular.

Como ya se ha comentado, en los casos en los que se planifica una carga inmediata, el requisito indispensable para su viabilidad es la obtención de una buena estabilidad primaria de los implantes. El objetivo de obtener una estabilidad primaria suficiente es disminuir al máximo el micromovimiento del implante en el hueso, dato que es especialmente importante en el maxilar superior, ya que presenta un hueso de peor calidad comparado con la mandíbula.

Un micromovimiento excesivo conduce a una fibrointegración y no a una correcta oseointegración. Actualmente se consideran aceptables micromovimientos de 50 a $150 \mu \mathrm{m}$ y se recomienda un torque de inserción superior a $32 \mathrm{Ncm}$. Con este torque de inserción las fibras de colágeno se forman con una orientación transversal y no paralela lo que lleva a una mayor y mejor resistencia al estrés mecánico tras la cicatrización $(78,87)$.

El micromovimiento se define como: el movimiento subclínico entre el implante y el hueso, y es menor en la mandíbula respecto al maxilar superior $(78,87)$.

Puede cuantificarse el micromovimiento mediante diferentes sistemas de registro, Becker y cols. (87), mi- 
den este parámetro mediante un análisis de frecuencia de resonancia que permite la obtención de un cociente de estabilidad (Implant Stabillity Quotient- ISQ), en un estudio de 100 casos consecutivos registrando el ISQ en el momento de la instalación del implante, obtuvieron buenos resultados en los colocados con un torque de inserción menor de $30 \mathrm{Ncm}$ y con un ISQ menor de 65 (cifras consideradas como mínimas para garantizar el éxito de un implante con carga inmediata).

Otras técnicas restauradoras son también útiles para ayudar en la oseointegración del implante sometido a carga funcional inmediata, tales como, la disminución del micro movimiento a través de la aplicación de estructuras rígidas para poder ferulizar los implantes, y la limitación de interferencias oclusales en los movimientos laterales de la mandíbula (88).

Koutouzis y cols. (88), evaluaron los resultados de implantes unitarios colocados con la técnica de osteótomos cargados de forma inmediata, al cabo de un año de su colocación y llegaron a la conclusión que esta técnica falló en demostrar que el torque de inserción del implante fuera mayor cuando se aplica esta técnica condensante. Los implantes colocados según esta técnica tenían más fracasos comparado con la técnica convencional de fresado óseo, que mostró una mínima perdida de hueso periimplantario después de 1 año de carga.

El concepto de carga inmediata requiere un alto conocimiento y experiencia al aplicar el plan de tratamiento implantológico, con un estudio radiográfico detallado, un examen clínico exhaustivo, un manejo quirúrgico cuidadoso y conceptos claros de prótesis sobre implantes para lograr un tratamiento correcto y exitoso. Cuando todo el procedimiento transcurre sin incidencias, el grado de satisfacción de los pacientes tras una rehabilitación del maxilar superior edéntulo atrófico con carga inmediata es muy elevado. Erkapers y cols. (89), concluyeron que la satisfacción de estos pacientes aumenta tras este tipo de tratamiento valorado mediante un cuestionario OHIP-49.

\section{IMPLANTES INIMEDIATOS}

La perdida de dientes y el edentulismo frecuentemente dan lugar a repercusiones psicológicas, sociales y profesionales negativas. La colocación de implantes inmediatos (II) y la posibilidad de ser cargados también de forma inmediata presenta a su vez, una serie de ventajas tanto sociales como económicas (90).
La colocación de II fue descrita por primera vez por Schulte y Heimke hace más de 30 años $(91,92)$.

Cuando comparamos las ventajas de la colocación inmediata de los implantes en comparación con la técnica diferida básicamente podemos establecer que: 1) disminuye el número de intervenciones quirúrgicas, 2) disminuye el tiempo de curación y 3) reduce el tiempo de tratamiento protésico, dando como resultado un beneficio psicológico para el paciente (90,93-95). También se han destacado como ventajas potenciales una mejor posición tridimensional del implante y la presunción de preservar el alveolo, siendo esto último muy discutido, ya que estudios recientes en animales y en humanos han demostrado que la colocación del II no influye en los cambios de remodelación ósea que se producen tras la extracción dentaria (90,91,96-100).

Son varios los trabajos que evalúan los cambios morfológicos en II, tanto de los tejidos blandos como de los tejidos duros periimplantarios y los comparan con implantes colocados siguiendo el protocolo convencional. También podemos encontrar estudios que evalúan las diferencias entre colocar los II a nivel crestal o subcrestal, la utilización complementaria de biomateriales, la carga inmediata o diferida y las diferentes técnicas quirúrgicas para la obtención de mejores resultados.

A lo largo de los años, la experiencia clínica ha marcado unos criterios básicos para un tratamiento con II exitoso: exodoncia atraumática, intervención quirúrgica mínimamente invasiva, estabilidad primaria del implante y la ausencia de micromovimientos $(90,92)$. A nivel del maxilar superior no siempre pueden observarse altos niveles de estabilidad, por lo que varios autores recomiendan la colocación más palatinizada de los implantes, el subfresado y la elección de un diámetro y longitud del implante adecuados para superar estas limitaciones anatómicas $(90,97)$. La colocación de II debería ser tan palatinizada como sea posible mientras se consiga mantener un perfil de emergencia óptimo y para muchos autores el defecto horizontal ("gap"), debería ser rellenado con un material de injerto como puede ser el hueso de origen bovino (96).

González-Martín y cols. (101) estudiaron la colocación de II con un fresado menor respecto al protocolo de fresado ( $28,6 \%$ menos) en la región apical. La calidad ósea en la parte más apical del implante se evaluó a los 6 meses mediante la tomografía computadorizada de haz cónico. Los resultados del estudio (solo 3 pa- 
cientes), muestran que no hay cambios radiológicos en la calidad ósea a los 6 meses cuando se efectúa un subfresado en la porción apical del implante y que esta técnica permite una inserción del implante a mayor torque. Norton (102) hizo un estudio retrospectivo en 61 pacientes donde se colocaran II con un torque de inserción bajo y una prótesis provisional inmediata. Su conclusión fue que la colocación de II con un torque de inserción de $25 \mathrm{Ncm}$ es suficiente para obtener elevadas tasas de éxito y niveles de hueso marginal similares a los implantes colocados de manera convencional, contradiciendo así a diferentes autores.

Diversas revisiones bibliográficas concluyen que el uso complementario de biomateriales mejora el proceso de formación ósea entre el implante y las paredes del alvéolo así como las tasas de supervivencia. Hasta la fecha, no se ha podido determinar cuál es el mejor material (injertos alogénicos, xenogénicos, autólogos y materiales aloplásticos) para el relleno del "gap" y que dimensiones mínimas debería tener el "gap" para ser necesaria la colocación de un injerto (1-2 mm) (92).

Varios estudios en animales evalúan la utilización de diferentes biomateriales junto a la colocación de II. Park y cols. (93), realizaron un estudio en perros para valorar si la colocación de II con una membrana no reabsorbible de PTFE-e (politetrafluoroetileno expandido) (Tefgen; Lifecore Biomedical, Chaska, MN, EE.UU.), colocada sobre la cortical vestibular de la región tratada con II y fijada con chinchetas, prevenía la reabsorción de la cortical vestibular, en comparación con los casos en los que no se colocaba la membrana. Estos autores concluyeron que en los lugares donde prima la estética, la colocación de una membrana puede ayudar a prevenir la reabsorción de la cortical vestibular que se produce tras la exodoncia. Araujo y cols. (96), por otro lado valoraron la colocación en el "gap" de un nuevo substituto óseo, el Bio-Oss $₫$ Collagen (GeistlichPharma AB, Wolhusen, Suiza) y los resultados que obtienen indican una mejoría en el proceso de curación ósea obteniendo una mayor cantidad de tejido duro en la entrada del alveolo y una mejoría en el nivel de hueso marginal en contacto con el implante. Estos autores utilizan implantes de diámetro más estrecho que en estudios anteriores originando un "gap" superior, lo que aparentemente parece promover la formación de hueso nuevo y mejorar el nivel de hueso en contacto con el implante cuando este "gap" es injertado (96).

En otros estudios se ha podido demostrar que la colocación de implantes de mayor diámetro para rellenar el "gap" no disminuye la reabsorción ósea de la cresta sino que la aumenta (99). Además, actualmente se asume que, la distancia de la superficie del implante a la superficie más externa de la cresta ósea alveolar ejerce una influencia significativa en la reabsorción de la cresta, más que las dimensiones del "gap" inicial o del diámetro del implante (103).

La ingeniería tisular ha sido también utilizada en el estudio de los II en perros, obteniendo resultados estadísticamente significativos a favor de su utilización. La ingeniería tisular permite crear un material que se adapta al espacio del defecto aportando grandes ventajas en la terapia implantológica (94). Caneva y cols. (103) en otro estudio en perros utilizaron hidroxiapatita enriquecida con magnesio en el relleno del "gap", observándose que este material no contribuyó de manera significativa para el mantenimiento del contorno de la cortical vestibular del alveolo.

En relación con los trabajos en humanos que evalúan la colocación de biomateriales junto a II podemos encontrar algunas series de casos (104-107) y estudios clínicos randomizados $(108,109)$. Yun y cols. (106), estudiaron la colocación de II en las zonas posteriores de los maxilares junto a una doble membrana (membrana de colágeno + membrana de politetrafluoroetileno de alta densidad - dPTFE), rellenándose el gap con material de injerto óseo. Con esta técnica se permite el cierre del alvéolo postextracción y la membrana de dPTFE puede quedarse expuesta, sin ser preciso el cierre del colgajo, facilitando la preservación de la encía queratinizada. Estos mismos autores concluyen que la utilización de materiales de injerto óseo en II puede ayudar al éxito del tratamiento por diferentes vías: 1) si se utiliza membrana se previene el colapso, 2) se estabiliza el coágulo y 3) permite rellenar el espacio entre implante y el hueso. Se recomienda que siempre que el "gap" sea mayor de $2 \mathrm{~mm}$ se coloque material de injerto óseo (92).

Otro de los posibles materiales que pueden emplearse en estos casos es el beta-fosfato-tricálcico, en un estudio clínico randomizado se pudo concluir que su utilización permitió mejorar la densidad ósea alrededor de los II cuando se comparó con los II sin relleno del espacio entre el hueso y el implante (108).

Angelis y cols. (109), en un estudio clínico randomizado multicéntrico, evaluaron si existían diferencias significativas entre la colocación de una membrana reabsorbible de colágeno "cross-linked" sola y la colocación de una membrana y material de injerto (membrana 
reabsorbible de colágeno "cross-linked" + cerámica de hidroxiapatita), llegando a la conclusión que la combinación de ambos materiales simultáneamente mejoraba los resultados estéticos en los II.

Con el objetivo de mejorar notablemente la calidad de vida de los pacientes y completar satisfactoriamente sus expectativas, la posibilidad de reducir drásticamente el tiempo entre la inserción del implante y la restauración funcional ha llevado a muchos autores a tener interés en la carga inmediata y temprana de los implantes. Por "inmediato" se entiende la aplicación de carga y fuerzas oclusales en implantes inmediatamente después de su colocación o dentro de las 48 horas, mientras que "temprana" es la aplicación de carga o fuerzas oclusales a partir de las 48 horas y en todo caso antes de que se cumpla el tiempo indicado en el protocolo estándar de espera (110). En la literatura existen varios estudios que comparan la colocación de II seguidos de carga funcional (111) (estética y carga inmediata) y II seguidos de carga no funcional (estética inmediata, no carga inmediata) $(110,112-114)$ con II cargados de manera tardía. Blanco y cols. (111), efectuaron un estudio a boca partida en animales con II, donde los II son cargados de forma inmediata en una hemiarcada y en otra no. Los resultados muestran tasas de supervivencia similares entre ambos grupos así como las dimensiones de los tejidos blandos periimplantarios a los 3 meses. El Chaar y cols. (115) hicieron un estudio retrospectivo donde evaluaron 235 II seguidos de la colocación de una restauración provisional sin función y la colocación de la restauración definitiva a las 2 semanas, obteniendo resultados similares a los II que fueron cargados de forma tardía.

Grandi y cols. (112) en un estudio multicéntrico donde se colocaron II seguidos de una restauración provisional sin función, a los 12 meses observaron tasas de éxito del $97,2 \%$. Malchiodi y cols. (110), colocaron II seguidos de carga no funcional y en este estudio observaron que la persistencia de la cresta interproximal parece ser el punto clave para mantener las condiciones ideales que necesitan los tejidos blandos. La cresta interproximal muestra una correlación estadísticamente significativa con el nivel de la papila interproximal y el nivel vestibular del margen gingival, siendo estos dos factores los más importantes para obtener resultados estéticos.

Otros autores (90) evaluaron la verdadera carga inmediata en humanos mediante un estudio clínico randomizado donde se colocaron 6 implantes inmediatos seguidos de una prótesis fija de arcada completa provisional y lo compararon con el mismo tratamiento pero con los implantes colocados una vez cicatrizado el alvéolo. Los autores no observaron diferencias significativas en los cambios de volumen óseo entre ambos grupos. Los resultados parecen indicar que la colocación de II y una carga inmediata sobre 5 o 6 implantes en un maxilar superior edéntulo puede efectuarse de manera exitosa, pero hay que tener en cuenta que en este estudio no toman, como parámetro comparativo inicial, las radiografías del momento de colocación de II, sino a partir de los 6 meses, por lo que los cambios entre los 0 y 6 meses no quedaron registrados.

Con el fin de disminuir los cambios morfológicos óseos tras la colocación de II, se ha estudiado la colocación de II sin levantar un colgajo mucoperióstico. La cirugía sin colgajo y la utilización de biomateriales en el "gap" parecen ser buenas opciones para minimizar la reabsorción de la cortical vestibular (116). Se ha podido observar que la colocación de más de un II contiguo da lugar a una mayor remodelación ósea en comparación con II unitarios (117).

La colocación de II subcrestales puede ser utilizada en áreas estéticas donde se ha sugerido que así se puede minimizar el riesgo de exposición del metal y permitir un espacio suficiente en la dimensión vertical para obtener un perfil de emergencia adecuado (98). Koh y cols. (91) realizaron un estudio clínico randomizado en 24 pacientes con un periodo de seguimiento de 4 meses, donde comparaban la colocación de II a nivel de la cresta palatina, con II colocados a nivel subcrestal ( $1 \mathrm{~mm}$ ). En este estudio no obtuvieron diferencias estadísticamente significativas en relación a los cambios en el nivel de la cresta ósea y de los tejidos blandos. Por el contrario, en la mismo línea Novaes Jr y cols. (116) en un estudio en perros, observaron una pérdida ósea mayor de la cortical vestibular en II colocados subcrestalmente.

Otro tema de discusión en II es su colocación en un lecho con lesiones periapicales previas. Se puede efectuar la colocación de un II en presencia de una lesión periapical, pero se precisa de un desbridamiento exhaustivo previo (118). Khademi y cols. (118) no encontraron diferencias significativas entre II colocados en alveolos con lesiones periapicales o sin lesión periapical o en los implantes colocados cuando la lesión periapical había curado. Bell y cols. (119) realizaron un estudio donde se evaluaron 922 implantes, de estos 285 se colocaron en zonas con una lesión periapical crónica previa y 637 en zonas sin signos de lesión periapical. No observaron diferencias estadísticamente significativas entre ambos grupos, pero observaron 
que cuando el II es colocado al lado de un diente con patología periapical la tasa de éxito fue significativamente inferior ( $81 \%$ vs. $100 \%)$.

En relación con las complicaciones como la periimplantitis, cuando se compara la colocación de II con la colocación de implantes diferidos en un mismo paciente, se ha observado una pérdida ósea y una tendencia mayor a la periimplantitis en II, aunque de manera no significativa en comparación con implantes diferidos (99).

La colocación de II, estaba dirigida principalmente para reemplazar dientes en los sectores estéticos (110). En el sector anterior, la gran mayoría de los autores concluyen que la colocación de II junto con la carga no funcional resulta un tratamiento predecible $(112,113)$. Sin embargo, algunos estudios observan que hay menor recesión gingival cuando se colocaban los implantes en dos tiempos, especialmente cuando se combina con la colocación de una membrana no reabsorbible, comparando con II no regenerados (120).

La colocación de II en sectores posteriores no es un procedimiento rutinario, ya que la exodoncia deja un gran defecto y la estabilidad primaria del II es cuestionada (121). Annibali y cols. (121) estudiaron las diferencias entre la colocación de implantes inmediatos, de formas temprana y tardía a nivel del primer molar del maxilar superior y de la mandíbula obteniendo tasas de éxito similares entre los cuatro grupos. La colocación de implantes temprana debe de ser una alternativa a tener en cuenta cuando las condiciones anatómicas no son favorables para la colocación de II. Block (95) estudió 35 casos en los que también obtiene tasas de éxito altas y similares a las de los implantes colocados de forma convencional en sectores posteriores.

Los estudios publicados durante el año 2011 que evalúan los II, presentan una gran heterogeneidad en su metodología. La gran mayoría tiene una muestra muy pequeña, y muchos son series de casos o estudios en animales. Se precisan por tanto; estudios clínicos randomizados, en humanos, con muestras mayores y con resultados a largo plazo para poder dar recomendaciones concluyentes basadas en la evidencia científica.

\section{AGRADECIMIENTOS}

Este artículo ha sido realizado por el grupo de investigación consolidado "Patología y Terapéutica Odontológica y Maxilofacial del Instituto de Investigación Biomédica de Bellvitge (IDIBELL).

\section{BIBLIOGRAFÍA}

1. Pommer B, Zechner W, Watzak G, Ulm C, Watzek G, Tepper G. Progress and trends in patients mindset on dental implants. I: Level of information, sources of information and need for patient information. Clin Oral Implants Res. 2011;22:223-9.

2. Carr A, Wolfaardt J, Garrett N. Capturing patient benefits of treatment. Int J Oral Maxillofac Implants. 2011;26 Suppl:85-92.

3. Balaguer J, Garcia B, Penarrocha M, Penarrocha M. Satisfaction of patients fitted with implant-retained overdentures. Med Oral Patol Oral Cir Bucal. 2011;16: e204-9.

4. Baracat LF, Teixeira AM, dos Santos MB, da Cunha Vde P, Marchini L. Patients' expectations before and evaluation after dental implant therapy. Clin Implant Dent Relat Res. 2011;13:141-5.

5. Laurell L, Lundgren D. Marginal bone level changes at dental implants after 5 years in function: A metaanalysis. Clin Implant Dent Relat Res. 201 1;13:19-28.

6. Degidi M, Perrotti V, Shibli JA, Novaes AB, Piattelli A, Iezzi G. Equicrestal and subcrestal dental implants: A histologic and histomorphometric evaluation of nine retrieved human implants. J Periodontol. 2011;82:70815.

7. Ivanovski S, Hamlet S, Salvi GE, Huynh-Ba G, Bosshardt DD, Lang NP, et al. Transcriptional profiling of osseointegration in humans. Clin Oral Implants Res. 201 1;22: 373-81.

8. Kuchler U, Luvizuto ER, Tangl S, Watzek G, Gruber R. Short-term teriparatide delivery and osseointegration: A clinical feasibility study. J Dent Res. 2011;90:1001-6.

9. Siddiqi A, Payne AG, De Silva RK, Duncan WJ. Titanium allergy: Could it affect dental implant integration? Clin Oral Implants Res. 2011;22:673-80.

10. Angelopoulos C, Aghaloo T. Imaging technology in implant diagnosis. Dent Clin North Am. 201 1;55:14158.

11. Kim YK, Park JY, Kim SG, Kim JS, Kim JD. Magnification rate of digital panoramic radiographs and its effectiveness for pre-operative assessment of dental implants. Dentomaxillofac Radiol. 201 1;40:76-83. 
12. Drago C, Carpentieri J. Treatment of maxillary jaws with dental implants: Guidelines for treatment. J Prosthodont. $2011 ; 20: 336-47$.

13. Braut V, Bornstein MM, Belser U, Buser D. Thickness of the anterior maxillary facial bone wall-a retrospective radiographic study using cone beam computed tomography. Int J Periodontics Restorative Dent. $2011 ; 31: 125-31$.

14. Yim JH, Ryu DM, Lee BS, Kwon YD. Analysis of digitalized panorama and cone beam computed tomographic image distortion for the diagnosis of dental implant surgery. J Craniofac Surg. 201 1;22:669-73.

15. Yin K, Wang Z, Fan X, Bian Y, Guo J, Lan J. The experimental research on two-generation BLB dental implants - Part I: Surface modification and osseointegration. Clin Oral Implants Res. 2012;23:846-52.

16. Chowdhary R, Chandraker N. Simple diagnostic method to assess the available bone for immediate implant placement in an extracted socket. J Oral Implantol. $2011 ; 37: 473-6$.

17. Luk LC, Pow EH, Li TK, Chow TW. Comparison of ridge mapping and cone beam computed tomography for planning dental implant therapy. Int J Oral Maxillofac Implants. 2011;26:70-4

18. Komiyama A, Pettersson A, Hultin M, Nasstrom $\mathrm{K}$, Klinge B. Virtually planned and template-guided implant surgery: An experimental model matching approach. Clin Oral Implants Res. 201 1;22:308-13.

19. Kehl M, Swierkot K, Mengel R. Three-dimensional measurement of bone loss at implants in patients with periodontal disease. J Periodontol. 201 1;82:68999.

20. Aglietta M, Siciliano VI, Rasperini G, Cafiero C, Lang NP, Salvi GE. A 10-year retrospective analysis of marginal bone-level changes around implants in periodontally healthy and periodontally compromised tobacco smokers. Clin Oral Implants Res. 201 1;22:47-53.

21. Rodríguez-Argueta OF, Figueiredo R, Valmaseda-Castellón E, Gay-Escoda C. Postoperative complications in smoking patients treated with implants: A retrospective study. J Oral Maxillofac Surg. 201 1;69: 2152-7.

22. Guimaraes RP, de Oliveira PA, Oliveira AM. Effects of induced diabetes and the administration of amino- guanidine in the biomechanical retention of implants: A study in rats. J Periodontal Res. 2011;46: 691-6.

23. von Wilmowsky C, Stockmann P, Harsch I, Amann K, Metzler $\mathrm{P}$, Lutz $\mathrm{R}$, et al. Diabetes mellitus negatively affects peri-implant bone formation in the diabetic domestic pig. J Clin Periodontol. 201 1;38:771-9.

24. Wang B, SongY,Wang F, Li D, Zhang H, Ma A, et al. Effects of local infiltration of insulin around titanium implants in diabetic rats. Br J Oral Maxillofac Surg. 201 1;49:225-9.

25. Kim JH, Park YB, Li Z, Shim JS, Moon HS, Jung HS, et al. Effect of alendronate on healing of extraction sockets and healing around implants. Oral Dis. 2011;17:705-11.

26. Manfredi M, Merigo E, Guidotti R, Meleti M, Vescovi P. Bisphosphonate-related osteonecrosis of the jaws: $A$ case series of 25 patients affected by osteoporosis. Int J Oral Maxillofac Surg. 2011;40:277-84.

27. Giro G, Coelho PG, Pereira RM, Jorgetti V, Marcantonio E,Jr, Orrico SR. The effect of oestrogen and alendronate therapies on postmenopausal bone loss around osseointegrated titanium implants. Clin Oral Implants Res. 2011;22:259-64.

28. Gaetti-Jardim EC, Santiago-Junior JF, Goiato MC, Pellizer EP, Magro-Filho O, Jardim Jr. EG. Dental implants in patients with osteoporosis: A clinical reality? J Craniofac Surg. 2011;22:1111-3.

29. Sammartino G, Marenzi G, Cioffi I, Tete S, Mortellaro C. Implant therapy in irradiated patients. J Craniofac Surg. 2011;22:443-5.

30. de Oliveira JA, do Amaral Escada AL, Alves Rezende MC, Mathor MB, Alves Claro AP. Analysis of the effects of irradiation in osseointegrated dental implants. Clin Oral Implants Res. 2012;23:511-4.

31. Barber AJ, Butterworth CJ, Rogers SN. Systematic review of primary osseointegrated dental implants in head and neck oncology. Br J Oral Maxillofac Surg. 201 1;49:29-36.

32. Dholam KP, Bachher GK, Yadav PS, Quazi GA, Pusalkar HA. Assessment of quality of life after implant-retained prosthetically reconstructed maxillae and mandibles postcancer treatments. Implant Dent. 201 1;20:85-94.

33. Palma-Carrio C, Maestre-Ferrin L, Penarrocha-Oltra D, Penarrocha-Diago MA, Penarrocha-Diago M. Risk factors associated with early failure of dental implants. 
A literature review. Med Oral Patol Oral Cir Bucal. $2011 ; 16: 514-7$.

34. Sakka S, Coulthard P. Implant failure: Etiology and complications. Med Oral Patol Oral Cir Bucal. 201 1;16: 42-4.

35. Oduncuoglu BF, Alaaddinoglu EE, Oguz Y, Uckan S, Erkut S. Repositioning a prosthetically unfavorable implant by vertical distraction osteogenesis. J Oral Maxillofac Surg. $2011 ; 69: 1628-32$.

36. Bacci C, Berengo M, Favero L, Zanon E. Safety of dental implant surgery in patients undergoing anticoagulation therapy: A prospective case-control study. Clin Oral Implants Res. $2011 ; 22: 151-6$.

37. Jo JH, Kim SG, Oh JS. Hemorrhage related to implant placement in the anterior mandible. Implant Dent. $2011 ; 20: 33-7$.

38. Katsumi Y, Tanaka R, Hayashi T, Koga T, Takagi R, Ohshima H.Variation in arterial supply to the floor of the mouth and assessment of relative hemorrhage risk in implant surgery. Clin Oral Implants Res. 2011; (Epub ahead of print).

39. Galindo-Moreno P, Padial-Molina M, Sánchez-Fernández E, Hernández-Cortés P, Wang HL, O’Valle F. Dental implant migration in grafted maxillary sinus. Implant Dent. $2011 ; 20: 400-5$.

40. Galindo-Moreno P, Padial-Molina M, Ávila G, Ríos HF, Hernández-Cortés $\mathrm{P}$, Wang $\mathrm{HL}$. Complications associated with implant migration into the maxillary sinus cavity. Clin Oral Implants Res. 2011 ;23:1152-60.

41. Soehardi A, Meijer GJ, Manders R, Stoelnga PJ. An inventory of mandibular fractures associated with implants in atrophic edentulous mandibles: a survey of Dutch oral and maxillofacial surgeons. Int J Oral Maxillofac Implants. 201 1;26:1087-93.

42. Juodzbalys G, Wang HL, Sabalys G, Sidlauskas A, Galindo-Moreno P. Inferior alveolar nerve injury associated with implant surgery. Clin Oral Implants Res. 2011 (Epub ahead of print).

43. Sharaf B, Dodson TB. Does the use of prophylactic antibiotics decrease implant failure? Oral Maxillofac Surg Clin North Am. 201 1;23:547-50.

44. Sharaf B, Jandali-Rifai M, Susarla SM, Dodson TB. Do perioperative antibiotics decrease implant failure? J Oral Maxillofac Surg. 201 1;69:2345-50.
45. Ferlito S, Liardo C, Puzzo S. Bisphosponates and dental implants: A case report and a brief review of literature. Minerva Stomatol. 2011;60:75-81.

46. Favia G, Piattelli A, Sportelli P, Capodiferro S, Iezzi G. Osteonecrosis of the posterior mandible after implant insertion: A clinical and histological case report. Clin Implant Dent Relat Res. 2011 ;13:58-63.

47. Tsetsenekou E, Papadopoulos T, Kalyvas D, Papaioannou $\mathrm{N}$, Tangl S, Watzek G. The influence of alendronate on osseointegration of nanotreated dental implants in New Zealand rabbits. Clin Oral Implants Res. 2012;23:65966.

48. Lee SJ, Oh TJ, Bae TS, Lee MH, Soh Y, Kim BI, et al. Effect of bisphosphonates on anodized and heat-treated titanium surfaces: An animal experimental study. J Periodontol. 201 1;82:1035-42.

49. Roccuzzo M, Bonino F, Bonino L, Dalmasso P. Surgical therapy of peri-implantitis lesions by means of a bovinederived xenograft: Comparative results of a prospective study on two different implant surfaces. J Clin Periodontol. 201 1;38:738-45.

50. Algraffee H, Borumandi F, Cascarini L. Peri-implantitis. Br J Oral Maxillofac Surg. 201 1;50:689-94.

51. Rodrigo D, Martín C, Sanz M. Biological complications and peri-implant clinical and radiographic changes at immediately placed dental implants. A prospective 5-year cohort study. Clin Oral Implants Res. 2012;23:1224-31.

52. Severino VO, Napimoga $\mathrm{MH}$, de Lima Pereira SA. Expression of IL-6, IL-10, IL-17 and IL-8 in the periimplant crevicular fluid of patients with peri-implantitis. Arch Oral Biol. 201 1;56:823-8.

53. Charalampakis F, Rabe P, Leonhardt A, Dahlén G. A follow-up study of peri-implantitis cases after treatment. J Clin Periodontol. 2011;38:864-71.

54. Candel-Marti ME, Flichy-Fernández AJ, Alegre-Domingo T, Ata-Ali J, Penarrocha-Diago MA. Interleukins IL-6, IL-8, IL-10, IL-12 and periimplant disease. An update. Med Oral Patol Oral Cir Bucal. 2011;16:518-21.

55. Sahm N, Becker J, Santel T, Schwarz F. Non-surgical treatment of peri-implantitis using an air-abrasive device or mechanical debridement and local application of chlorhexidine: A prospective, randomized, controlled clinical study. J Clin Periodontol 201 1;38:872-8. 
56. Ata-Ali J, Candel-Marti ME, Flichy-Fernández AJ, Penarrocha-Oltra D, Balaguer-Martínez JF, Penarrocha Diago M. Peri-implantitis: Associated microbiota and treatment. Med Oral Patol Oral Cir Bucal. 2011;16:93743.

57. Aljateeli M, Fu JH, Wang HL. Managing peri-implant bone loss: Current understanding. Clin Implant Dent Relat Res. 2012;14 Suppl:109-18.

58. Persson GR, Roos-Jansaker AM, Lindahl C, Renvert S. Microbiologic results after non-surgical Erbium-doped:Yttrium, aluminum, and garnet laser or air-abrasive treatment of peri-implantitis: A randomized clinical trial.J Periodontol. 2011;82:1267-78.

59. Rinke S, Ohl S, Ziebolz D, Lange K, Eickholz P. Prevalence of periimplant disease in partially edentulous patients: A practice-based cross-sectional study. Clin Oral Implants Res. 2011;22:826-33.

60. Lang NP, Bosshardt DD, Lulic M. Do mucositis lesions around implants differ from gingivitis lesions around teeth? J Clin Periodontol. 201 1;38 Suppl:182-7.

61. Lang NP, Berglundh T, Working group 4 of seventh European workshop on Periodontology. Periimplant diseases: Where are we now? Consensus of the seventh European workshop on Periodontology.J Clin Periodontol. $2011 ; 38$ Suppl:178-81.

62. Donos N, Hamlet S, Lang NP, Salvi GE, Huynh-Ba G, Bosshardt DD, et al. Gene expression profile of osseointegration of a hydrophilic compared with a hydrophobic microrough implant surface. Clin Oral Implants Res. 2011;22:365-72.

63. Bosshardt DD, Salvi GE, Huynh-Ba G, Ivanovski S, Donos $\mathrm{N}$, Lang NP. The role of bone debris in early healing adjacent to hydrophilic and hydrophobic implant surfaces in man. Clin Oral Implants Res. 2011;22:35764.

64. Abdel-Haq J, Karabuda CZ, Arisan V, Mutlu Z, Kurkcu M. Osseointegration and stability of a modified sandblasted acid-etched implant: An experimental pilot study in sheep. Clin Oral Implants Res. 201 1;22:265-74.

65. Artzi Z, Nemcovsky CE, Tal H, Weinberg E, Weinreb M, Prasad $\mathrm{H}$, et al. Clinical and histomorphometric observations around dual acid-etched and calcium phosphate nanometer deposited-surface implants. Int J Oral Maxillofac Implants. 201 1;26:893-901.
66. Collaert B, Wijnen L, De Bruyn H. A 2-year prospective study on immediate loading with fluoride-modified implants in the edentulous mandible. Clin Oral Implants Res. 2011;22:1111-6.

67. Al-Hamdan K, Al-Moaber SH, Junker R, Jansen JA. Effect of implant surface properties on peri-implant bone healing: A histological and histomorphometric study in dogs. Clin Oral Implants Res. 2011;22:399405 .

68. Aloy-Prosper A, Maestre-Ferrin L, Penarrocha-Oltra D, Penarrocha-Diago M. Marginal bone loss in relation to the implant neck surface: An update. Med Oral Patol Oral Cir Bucal. 2011 ; 16:365-8.

69. den Hartog L, Meijer HJ, Stegenga B, Tymstra N, Vissink A, Raghoebar GM. Single implants with different neck designs in the aesthetic zone: A randomized clinical trial. Clin Oral Implants Res. 201 1;22:1289-97.

70. Aloy-Prosper A, Maestre-Ferrin L, Penarrocha-Oltra D, Penarrocha-Diago M. Bone regeneration using particulate grafts: An update. Med Oral Patol Oral Cir Bucal. 201 1;16: 210-4.

71. Albouy JP, Abrahamsson I, Persson LG, Berglundh T. Implant surface characteristics influence the outcome of treatment of peri-implantitis: An experimental study in dogs. J Clin Periodontol. 201 1;38:58-64.

72. Bartold PM, Kuliwaba JS, Lee V, Shah S, Marino V, Fazzalari $\mathrm{NL}$. Influence of surface roughness and shape on microdamage of the osseous surface adjacent to titanium dental implants. Clin Oral Implants Res. 2011 ; $22: 613-8$

73. Koutouzis T, Wallet S, Calderon N, Lundgren T. Bacterial colonization of the implant-abutment interface using an in vitro dynamic loading model. J Periodontol. $2011 ; 82: 613-8$.

74. Nishioka RS, de Vasconcellos LG, de Melo Nishioka GN. Comparative strain gauge analysis of external and internal hexagon, Morse taper, and influence of straight and offset implant configuration. Implant Dent. 201 1;20: 24-32.

75. Baffone GM, Botticelli D, Pantani F, Cardoso LC, Schweikert MT, Lang NP. Influence of various implant platform configurations on peri-implant tissue dimensions: An experimental study in dog. Clin Oral Implants Res. $2011 ; 22: 438-44$. 
76. Lesmes D, Laster Z. Innovations in dental implant design for current therapy. Oral Maxillofac Surg Clin North Am. 2011;23:193-200.

77. Enkling N, Johren $\mathrm{P}$, Klimberg T, Mericske-Stern R, Jervoe-Storm PM, Bayer S, et al. Open or submerged healing of implants with platform switching: A randomized, controlled clinical trial. J Clin Periodontol. $2011 ; 38: 374-84$.

78. Boedeker D, Dyer J, Kraut R. Clinical outcome of immediately loaded maxillary implants: A 2-year retrospective study. J Oral Maxillofac Surg. 201 1;69: 1335-43.

79. Fung K, Marzola R, Scotti R, Tadinada A, Schincaglia GP. A 36-month randomized controlled split-mouth trial comparing immediately loaded titanium oxideanodized and machined implants supporting fixed partial dentures in the posterior mandible. Int J Oral Maxillofac Implants. 201 1;26:631-8.

80. Chung S, McCullagh A, Irinakis T. Immediate loading in the maxillary arch: Evidence-based guidelines to improve success rates: A review. J Oral Implantol. 2011 ; 37:610-21.

81. Eccellente T,Piombino M, Piattelli A, D'Alimonte E, Perrotti V, Iezzi G. Immediate loading of dental implants in the edentulous maxilla. Quintessence Int. 201 1;42: 281-9.

82. Linares A, Mardas N, Dard M, Donos N. Effect of immediate or delayed loading following immediate placement of implants with a modified surface. Clin Oral Implants Res. $2011 ; 22: 38-46$.

83. Strietzel FP, Karmon B, Lorean A, Fischer PP. Implantprosthetic rehabilitation of the edentulous maxilla and mandible with immediately loaded implants: Preliminary data from a retrospective study, considering time of implantation. Int J Oral Maxillofac Implants. 201 1;26:13947.

84. Khorshid HE, Hamed HA, Aziz EA. The effect of two different immediate loading protocols in implantsupported screw-retained prostheses. Implant Dent. 2011;20:157-66.

85. Browaeys H, Defrancq J, Dierens MC, Miremadi R, Vandeweghe $\mathrm{S}$, Van de Velde $\mathrm{T}$, et al. A retrospective analysis of early and immediately loaded osseotite implants in cross-arch rehabilitations in edentulous maxillas and mandibles up to 7 years. Clin Implant Dent Relat Res. 2012 ;23:1224-31.
86. Elsyad MA, Al-Mahdy YF, Fouad MM. Marginal bone loss adjacent to conventional and immediate loaded two implants supporting a ball-retained mandibular overdenture: A 3-year randomized clinical trial. Clin Oral Implants Res. $2011 ; 23: 496-503$.

87. Becker CM, Wilson TG,Jr, Jensen OT. Minimum criteria for immediate provisionalization of single-tooth dental implants in extraction sites: A 1-year retrospective study of 100 consecutive cases. J Oral Maxillofac Surg. 2011;69: 491-7.

88. Koutouzis T, Koutouzis G, Tomasi C, Lundgren T. Immediate loading of implants placed with the osteotome technique: One-year prospective case series. J Periodontol. 201 1;82:1556-62.

89. Erkapers M, Ekstrand K, Baer RA, Toljanic JA, Thor A. Patient satisfaction following dental implant treatment with immediate loading in the edentulous atrophic maxilla. Int J Oral Maxillofac Implants. 201 1;26:356-64.

90. Barbier L, Abeloos J, De Clercq C, Jacobs R. Periimplant bone changes following tooth extraction, immediate placement and loading of implants in the edentulous maxilla. Clin Oral Investig. 2012;16:106170.

91. Koh RU, Oh TJ, Rudek I, Neiva GF, Misch CE, Rothman ED, et al. Hard and soft tissue changes after crestal and subcrestal immediate implant placement. J Periodontol. 2011;82:1112-20.

92. Ortega-Martínez J, Pérez-Pascual T, Mareque-Bueno S, Hernández-Alfaro F, Ferres-Padro E. Immediate implants following tooth extraction. A systematic review. Med Oral Patol Oral Cir Bucal. 2012;17:251-61.

93. Park SY, Kye SB, Yang SM, Shin SY. The effect of nonresorbable membrane on buccal bone healing at an immediate implant site: An experimental study in dogs. Clin Oral Implants Res. $2011 ; 22: 289-94$.

94. Han X, Liu H, Wang D, Su F, Zhang Y, Zhou W, et al. Alveolar bone regeneration around immediate implants using an injectable $\mathrm{nHAC} / \mathrm{CSH}$ loaded with autogenic bloodacquired mesenchymal progenitor cells: An experimental study in the dog mandible. Clin Implant Dent Relat Res. 2011 (Epub ahead of print).

95. Block MS. Placement of implants into fresh molar sites: Results of 35 cases. J Oral Maxillofac Surg. 2011;69: 170-4. 
96. Araujo MG, Linder E, Lindhe J. Bio-Oss collagen in the buccal gap at immediate implants: A 6-month study in the dog. Clin Oral Implants Res. 2011;22:1-8.

97. Mangano F, Mangano C, Piattelli A, Sammons R, Ricci M, d'Avila S, et al. Esthetic evaluation of single-tooth morse taper connection implants placed in fresh extraction sockets or healed sites. J Oral Implantol. 2011 (Epub ahead of print).

98. Negri B, Calvo-Guirado JL, Pardo-Zamora G, RamírezFernández MP, Delgado-Ruiz RA, Munoz-Guzon F. Periimplant bone reactions to immediate implants placed at different levels in relation to crestal bone. Part I: A pilot study in dogs. Clin Oral Implants Res. 2012;23:228-35.

99. Rodrigo D, Martín C, Sanz M. Biological complications and peri-implant clinical and radiographic changes at immediately placed dental implants. A prospective 5-year cohort study. Clin Oral Implants Res. 2012;23:1224-31.

100. Calvo-Guirado JL, Mate-Sánchez J, Delgado-Ruiz R, Ramírez-Fernández MP, Cutando-Soriano A, Pena M. Effects of growth hormone on initial bone formation around dental implants: A dog study. Clin Oral Implants Res. 2011;22:587-93.

101. González-Martín O, Lee EA, Veltri M. CBCT fractal dimension changes at the apex of immediate implants placed using undersized drilling. Clin Oral Implants Res. 2012;23:954-7.

102. Norton MR. The influence of insertion torque on the survival of immediately placed and restored single-tooth implants. Int J Oral Maxillofac Implants. 201 1;26:1333-43.

103. Caneva M, Botticelli D, Stellini E, Souza SL, Salata LA, Lang NP. Magnesium-enriched hydroxyapatite at immediate implants: A histomorphometric study in dogs. Clin Oral Implants Res. 201 1;22:512-7.

104. Neves M, Correia A, Coutinho Alves C. A novel approach to preserve the buccal wall in immediate implant cases: A clinical report. J Oral Implantol. 2011 (Epub ahead of print).

105. Waasdorp J, Feldman S. Bone regeneration around immediate implants utilizing a dense PTFE membrane without primary closure: A report of 3 cases. J Oral Implantol. 2011 (Epub ahead of print).

106. Yun JH, Jun CM, Oh NS. Secondary closure of an extraction socket using the double-membrane guided bone regeneration technique with immediate implant placement. J Periodontal Implant Sci. 201 1;41:253-8.

107. Tsuda H, Rungcharassaeng K, Kan JY, Roe P, Lozada JL, Zimmerman G. Peri-implant tissue response following connective tissue and bone grafting in conjunction with immediate single-tooth replacement in the esthetic zone: A case series. Int J Oral Maxillofac Implants. $2011 ; 26: 427-36$.

108. Daif ET. Effect of a multiporous beta- tricalicum phosphate on bone density around dental implants inserted into fresh extraction sockets. J Oral Implantol. 2011 (Epub ahead of print).

109. Angelis N, Felice P, Pellegrino G, Camurati A, Gambino P, Esposito M. Guided bone regeneration with and without a bone substitute at single post-extractive implants: 1-year post-loading results from a pragmatic multicentre randomised controlled trial. Eur J Oral Implantol. $2011 ; 4: 313-25$.

110. Malchiodi L, Cucchi A, Ghensi P, Nocini PF. Evaluation of the esthetic results of 64 nonfunctional immediately loaded postextraction implants in the maxilla: Correlation between interproximal alveolar crest and soft tissues at 3 years of follow-up. Clin Implant Dent Relat Res. 2011 (Epub ahead of print).

111. Blanco J, Carral C, Linares A, Pérez J, Muñoz F. Soft tissue dimensions in flapless immediate implants with and without immediate loading: An experimental study in the beagle dog. Clin Oral Implants Res. 2012;23:70-5.

112. Grandi T, Garuti G, Samarani R, Guazzi P, Forabosco A. Immediate loading of single post-extractive implants in the anterior maxilla: 12-month results from a multicenter clinical study.J Oral Implantol. 2011 (Epub ahead of print).

113. di Felice R, D'Amario M, De Dominicis A, Garocchio S, D'Arcangelo C, Giannoni M. Immediate placement of bone level Sraumann implants: A case series. Int J Periodontics Restorative Dent. 2011;31:57-65.

114. El-Chaar ES. Immediate placement and provisionalization of implant-supported, single-tooth restorations: A retrospective study. Int J Periodontics Restorative Dent. 2011;31:409-19.

115. El Chaar E, Bettach R.Withdrawn: Immediate placement and provisionalization of implant-supported, singletooth restorations: A retrospective study. J Oral Implantol 2012 2012;38:434-45. 
116. Novaes-Jr AB, Suaid FA, Queiroz AC, Muglia VA, Souza SL, Palioto DB, et al. Buccal bone plate remodeling after immediate implant with and without synthetic bone grafting and flapless surgery. Radiographic study in dogs. J Oral Implantol. 2011 (Epub ahead of print).

117. Al-Shabeeb MS, Al-Askar M, Al-Rasheed A, Babay N, Javed F, Wang HL, et al. Alveolar bone remodeling around immediate implants placed in accordance with the extraction socket classification - A three-dimensional micro-computed tomography analysis. J Periodontol. 2012;83:981-7.

118. Khademi A, Shadmehr E, Ajami M, Rismanchian M, Razavi SM. Histologic and histomorphometric assessment of implants and periapical tissues when placed in the sockets of extracted teeth, teeth with periapical lesions and healed lesions: A canine study. J Oral Implantol. 2011 (Epub ahead of print).

119. Bell CL, Diehl D, Bell BM, Bell RE. The immediate placement of dental implants into extraction sites with periapical lesions: A retrospective chart review. J Oral Maxillofac Surg. 201 1;69:1623-7.

120. Miyamoto Y, Obama T. Dental cone beam computed tomography analyses of postoperative labial bone thickness in maxillary anterior implants: Comparing immediate and delayed implant placement. Int J Periodontics Restorative Dent. 201 1;31:215-25.

121. Annibali S, Bignozzi I, Iacovazzi L, La Monaca G, Cristalli MP. Immediate, early, and late implant placement in firstmolar sites: A retrospective case series. Int J Oral Maxillofac Implants. 201 1;26:1 108-22.

\section{CORRESPONDENCIA}

Prof. Dr. Cosme Gay Escoda

Centro Médico Teknon

Vilana, 12

08022 Barcelona

E-mail: cgay@ub.edu

http://www.gayescoda.com 